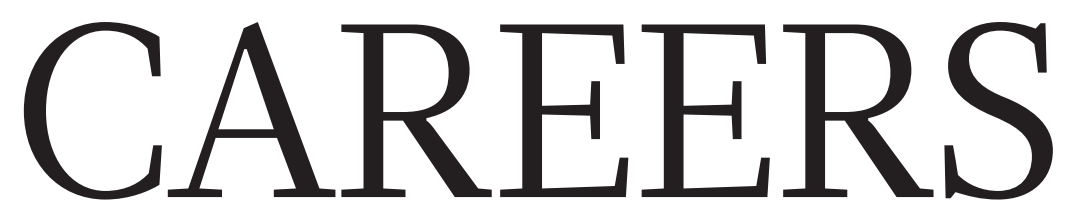

CHILLY CULTURE Male environment linked to dropouts by female researchers $\mathbf{p . 5 5 1}$

CONFERENCE COMFORT Female scientists call for child-friendly settings $\mathbf{p . 5 5 1}$
BLOG Personal stories and careers counsel http://blogs.nature.com/naturejobs

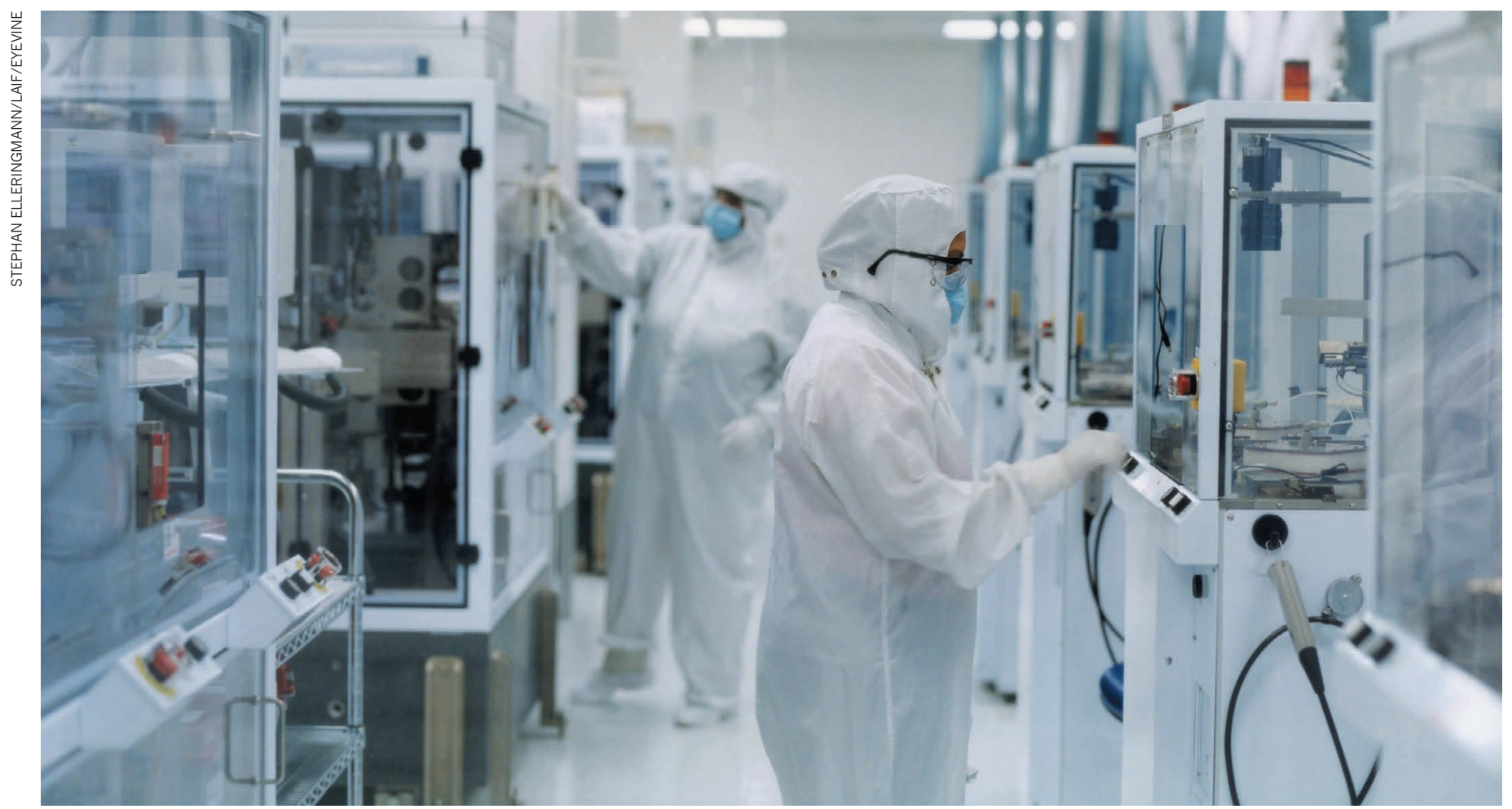

Scientists at the biotechnology company Affymetrix in Santa Clara, California. Positions in the biotechnology sector are highly sought after.

TRANSITIONS

\title{
Industrial strength
}

\section{Life-science industry insiders offer tips on how to beat job competitors.}

\section{BY KENDALL POWELL}

$\mathrm{W}$

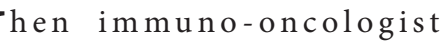
Martijn Bijker decided to move from academia to industry, he asked a friend to review his $\mathrm{CV}$. His friend who had worked in the pharmaceutical sector for two decades - told him to relegate his lists of publications, posters and presentations to the back of the document. The focus, he said, should be on teamwork skills and the ability to perform the job requirements.

The advice was an eye-opener for Bijker. He was used to the academic hierarchy, which values individual achievements above all else. But in corporate research, candidates must focus on collaboration.

Bijker subsequently founded From Science to Pharma, a consultancy and recruitment firm based in Sydney, Australia. He now regularly issues similar counsel to scientists hoping to shift from academia to industry, encouraging them to flip their $\mathrm{CV}$ - and their mindset to reflect the differences between the sectors.

Biotechnology and pharmaceutical industry positions are attractive to many recent $\mathrm{PhD}$ graduates - and are thus highly competitive. More than half of the respondents to Nature's 2017 Graduate Student Survey said that they would like to work in industry, and nearly one-quarter said an industrial position was what they most wanted.

Researchers who seek these jobs must switch from touting their publications, awards and citations to highlighting the value they bring to a team effort. They also need to identify their vocational strengths and talents, such as communication and management skills that transcend bench-top prowess and technical proficiency.

\section{THE SWITCH TO INDUSTRY}

Junior researchers who are considering industry should aim as soon as possible to develop the skills and expertise that will be attractive to hiring managers, says Alaa Abdine, a PhD-trained biophysicist who is now an executive recruiter for Crossover Search in New York City, which specializes in biotechnology companies. In last year's graduate-student survey, just $20 \%$ of respondents had sought the advice of a researcher who held the job they wanted, and only one-third received input on non-academic careers from their advisers. "Don't wait until your eighth year of a postdoc and then come to a recruiter looking for a job," says Abdine. 
Those who have made the switch to industry recommend that researchers identify their goals and interests before they launch a job search. After applying for a few different types of job, Forum Raval - who has a PhD in immunology and virology - realized that she really wanted to do translational research, developing products or procedures that would help people.

When discussing a friend's job in genetic testing, she realized that it fitted with her vision of translational research, even if it did not perfectly match her academic background. She managed to get an interview with Quest Diagnostics, a health-care diagnostic firm in Marlborough, Massachusetts, despite lacking solid genetics credentials on her CV. In the interview, she banked on selling the skills she had obtained during her $\mathrm{PhD}$, which required her to adapt and switch between complex tasks. "I was sweating the whole time," she recalls.

She got the job. Now, as a scientist at Quest, she analyses data from people with hard-todiagnose disorders, to determine whether the disorders have a genetic basis and, perhaps, a therapeutic solution. "I'm loving it," she says. "I'm still using my brain for science and directly helping people."

Researchers mulling over the switch to industry should also consider whether they are driven by the singular pursuit of their own ideas. "This is more difficult to do in industry, where research goals are usually set more narrowly," says Praveen Kumar Vemula, a biomaterials scientist at the Institute for Stem Cell Biology and Regenerative Medicine in Bangalore, India. Although he has remained in academic research, where he has the freedom to develop his own ideas, he has deep ties to India's biotechnology industry and has spun off several companies and licensed his technologies to others. To excel in industry, he says, means collaborating with others.

\section{DO YOUR HOMEWORK}

Job seekers must show a deep understanding of the company that interests them, such as its products, workplace culture, history, competitors, business-development plans, regulatory challenges and how it fits into the marketplace. They must also know a great deal about the position they want. Martin Rees, who is now a regional medical director in the Sydney office of biopharmaceutical company Stallergenes Greer, gave himself six months to learn everything he could about becoming a medical science liaison (MSL) a couple of years ago. An MSL is a scientific expert in a pharmaceutical or biotech company who liaises between the firm and the medical and scientific professionals who use its products.

He met informally over coffee with MSLs from different businesses and with marketing and salespeople from those companies to learn about the employers' cultures, products and competition (see P. Fiske Nature 538, 417-418; 2016). "You have to do your homework. That's

\section{APPLICATIONS AND INTERVIEWS Get yourself prepared for a transition to industry}

\section{Shine on paper}

- Review the CV of someone with the job you want or who works at the company you're targeting. Note the formatting and length. - Put long lists of publications, posters and presentations at the end of your CV or don't include them at all.

- Consider including a section such as 'Most Relevant 5 out of 20 Publications', so that employers are able to see your overall productivity without having to wade through a long list.

- Use active, past-tense verbs such as 'implemented', 'designed' or 'developed' to convey results accomplished.

\section{Be polished in person}

During an interview, you should back up statements about your skills, whether hard or soft, with real-world examples from your PhD or postdoctoral work. Don't discuss other job options or interviews with anyone on the interview team. Here are a few examples of 'curve ball' interview scenarios. - Give an example of a time you overcame a

really what's going to get you through the door for an interview," says Rees.

Professional associations can help to provide an inside view of companies' operations. The chapter of the Association for Women in Science in San Diego, California, for example, offers tours of local biotechnology and pharmaceutical companies for its members.

Job seekers should also spell out to hiring managers and other interviewers exactly how they will fit into a prospective employer's portfolio and mission. In 2017, the scientific recruitment company C-Drive in Bangalore conducted a survey of Indian companies in the life and chemical sciences, and it found that firms looking to hire $\mathrm{PhDs}$ and postdocs are especially frustrated by the candidates' lack of awareness about the company and its scientific context. If a cell biologist, for example, is vying for a job at a biotech firm or drugmaker that specializes in cancer treatments, the candidate should show in their application how their background fits with the target company's drug or molecular pipeline. "Many times there is a connection," says Shyam Suryanarayanan, who is chief executive of C-Drive and founded a partner company that provides industry-readiness training. "But it's not up to the employer to try to figure it out."

\section{INDUSTRY CONTACTS}

In the hyper-competitive environment of industry, getting a foot in the door can often depend on a researcher's contacts in a sector or particular company. Barbara Preston,

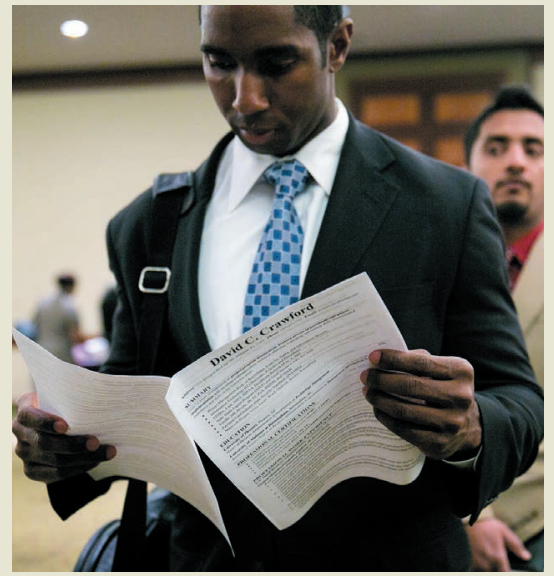

Industry-ready CVs need a targeted approach.

frustration with a colleague.

- Explain how you handle criticism.

- Tell us, why should we hire you rather than someone else?

- Talk about a time you failed.

- Take a timed test to write a short data-

analysis computer program. K.P. co-founder of recruiting firm PharmaScouts in San Diego, recommends that researchers build their networks by using LinkedIn to contact scientists who share research interests, backgrounds or even hobbies. If the junior researcher is attending an upcoming conference that the company scientist is also likely to attend, it's ideal to get in touch beforehand and ask to meet over coffee. "Use your position as a graduate student or postdoc as a plus, not a minus," Preston says, adding that it's important to be honest and direct but not to ask for a job. "Say, 'I'm coming up to a decision point in my career, and I want to make an informed decision. Can I ask you a few questions about your experience in industry?"'

Even researchers who have high-impact publications should seek contacts who work for their target companies. Those contacts could offer personal introductions, or they could put the researcher's name forward to set them apart from competing applicants. "Networking is the number-one thing anyone needs for getting any job," says Abdine.

Graduate students and postdocs should aim to find an academic adviser who has links to local companies, as Vemula does. It can also be helpful to develop a connection with lab heads in the student's or postdoc's speciality who have spun off their own business, because they are also likely to have industry contacts. Vemula, for example, encourages his industryinterested lab members to help prepare for and sit in on the biweekly or monthly meetings 
with his industry collaborators to discuss a project's progress and timelines. "Executing projects is very different with industry partners, and the lab members get first-hand experience in what an industry job will be like," says Vemula.

Other, more formal initiatives help junior researchers to connect with industry leaders. Australia launched a programme in 2017 to encourage doctoral students in the sciences to team up with industry-based mentors over the course of a year. Fourteen of the nation's 40 universities participate in the Industry Mentoring Network in STEM (IMNIS) programme, which matches about 200 science students with mentors. The pairs meet monthly, and students may get a workplace tour or invitation to industry networking events, for example. "It's a great opportunity for open conversation at an early stage of the student's career and gives students a chance to expand their networks," says Marguerite Evans-Galea, IMNIS executive director.

Evans-Galea says that, in Australia, nearly $70 \%$ of industry positions are not advertised because they are filled through word of mouth. Abdine says the same about entry-level research positions in the large US biotechnology hubs of San Francisco and San Diego in California, and Boston in Massachusetts.

\section{CAREER KEYWORDS}

Researchers who want to transition into industry will need to convert their academic $\mathrm{CV}$ into one that is specifically appropriate for industry. They should also prepare for an interview process that is different from that in academia (see 'Get yourself prepared for a transition to industry').

Industry insiders suggest that the researcher write an eight- to ten-bulletpoint summary at the top of their CV that highlights their training, background, career goals and skills, using keywords that will grab the attention of the first screener - probably a human-resources officer who may not have a scientific background. Those keywords should be the same ones that the hiring company used in its job advertisement, particularly in the sections that discuss the job's requirements and the company's research goals. "This is like the abstract of a paper is this interesting enough to read the rest of the paper? If not, your CV goes into the trash pile," Bijker says.

An industry CV, known in the United States as a résumé, should reflect the candidate's productivity, communication skills and innovation, says Preston. "Did you initiate a project, implement a new technique, or optimize an assay? What was innovative about your research? What did you shed light on to change scientific understanding?" She recommends the site www.scientificresumes. com, a service developed by scientists to help

researchers convert academic CVs into those appropriate for industry.

The interview itself is likely to include queries on workplace behaviour. And candidates should prepare for unexpected requests, such as "Tell me a joke". Preston says that these 'curve ball' scenarios can help screeners to identify candidates who can think quickly or who might have inappropriate biases.

Interviewees might also receive a research case study or roadblock to solve on the spot. Raval says that, during an interview, candidates should be comfortable admitting if

"You have to do your homework. That's really what's going to get you through the door for an interview." they don't have an answer, but should also use the opportunity to explain their thought process. "Saying 'I don't know, but my guess would be ...' is a very hard thing to say in an interview," she concedes. "But if you show them how you think, sometimes that's more informative than the actual answer."

Most final shortlisted applicants will be asked to give a scientific presentation. Preston recommends that candidates ask the hiring manager what types of people will be in the audience and what they would like to hear. "Be prepared to tell a story," she says, adding that candidates should remember that important audience members are not likely to be technical specialists, so talking points and slides need to be accessible. Employers will be listening for a candidate's research thought process and for their communication and working style, Preston adds. "The presentation can make or break you," she says.

Recruiters and hiring managers stress that junior researchers need to prepare immediately once they decide to transition to industry. "A lot of people have done a $\mathrm{PhD}$ and gone on to a postdoc by default," says Suryanarayanan. But, he says, those researchers are often only delaying the inevitable. "You should figure out who you are," he says. "It's good to think about what you want to do and what you are good at - but think about it before you feel cornered into an existential crisis."

Kendall Powell is a freelance science writer based in Lafayette, Colorado.

\section{CLARIFICATION}

The Careers feature 'The write stuff' (Nature 555, 129-130; 2018) should have made clear that Altmetric is part of Digital Science, a company owned by Holtzbrinck Publishing Group, which is also the majority shareholder in Nature's publisher, Springer Nature. Nature Research Editing Services is also owned by Springer Nature.

\section{CHILLY CULTURE}

\section{Women forced out}

A male-dominated workplace and a competitive culture that often shuts out family life might be contributing to the decline in the proportion of women at successive stages in research. In a qualitative study of 28 US female $\mathrm{PhD}$ students in physical sciences and engineering, led by Bianca Bernstein at Arizona State University in Tempe (M. Cabay et al. Soc. Sci. 7, 23; 2018), 12 said that they did not want to pursue research careers. Of those, 6 blamed their workplace environment and culture, including 2 who said they could no longer work within a male-heavy profession. Some of the female students reported that they felt ignored, dismissed or excluded from scientific conversations and other lab interactions among male colleagues. One said that a male colleague attributed her winning a scholarship to her gender and to quota filling. Some of the female students also reported being asked disproportionately often to perform 'women's work', such as cleaning up the lab or performing clerical duties.

\section{DIVERSITY}

\section{Open doors to children}

Conference organizers must make their events more welcoming and accessible to parents of young children, say 46 scientist-parents. Rebecca Calisi, a behavioural neuroscientist at the University of California, Davis, and her colleagues offer a blueprint for improving attendees' experience (R. M. Calisi et al. Proc. Natl Acad. Sci. USA http://doi.org/ ck8h; 2018). By not accommodating children, the authors say, conferences can unintentionally create barriers that exclude large numbers of scientists - especially mothers at an early stage of their career who might not be able to afford childcare. "One part of promoting diversity is supporting women with children," Calisi says. Rules about children seem to change from conference to conference and even from hour to hour, says Calisi, who notes that researchers with babies were barred from a poster session at a large conference last November, even though the official policy permitted children in the exhibition area. A practical, comfortable space for breastfeeding or pumping breast milk is an important provision, Calisi says. The Society for Neuroscience, for one, aims to become more inclusive. "The society is exploring ways to enhance the spaces for nursing mothers," says spokesperson Kara Flynn. 